\title{
An improved physical and genetic map of Campylobacter jejuni NCTC 11168 (UA580)
}

\author{
Andrey V. Karlyshev, ${ }^{1}$ John Henderson, ${ }^{2}$ Julian M. Ketley ${ }^{2}$ \\ and Brendan W. Wren'
}

Author for correspondence: Brendan W. Wren. Tel: +44 171601 8411. Fax: +44 1716018409. e-mail: b.w.wren@mds.qmw.ac.uk

\begin{abstract}
1 Department of Medical Microbiology, St Bartholomew's and the Royal London School of Medicine and Dentistry, West Smithfield, London EC1A 7BE, UK

2 Department of Genetics, University of Leicester, Leicester LE1 7RH, UK
\end{abstract}

\begin{abstract}
Campylobacter jejuni is recognized as the major cause of food-borne gastrointestinal disease in the developed world. To facilitate the molecular genetic analysis of this pathogen, an approximately 18-fold redundant Tropist3 cosmid library was constructed from C. jejuni NCTC 11168 genomic DNA. The cosmid library was partially ordered by hybridization to 15 pulsedfield electrophoresis (PFGE) restriction fragments. This analysis confirmed the estimated size of the genome to be $1730 \mathrm{~kb}$, but suggested discrepancies in some regions of the published physical map. The precise locations of two of the three rRNA gene clusters were mapped using a combination of restriction fingerprinting, sample sequencing and riboprobing. Additionally, 15 further genes were located on the revised map. A more detailed physical and genetic map of C. jejuni NCTC 11168 is presented.
\end{abstract}

Keywords: Campylobacter jejuni NCTC 11168, cosmid library, physical and genetic mapping, PFGE

\section{INTRODUCTION}

Campylobacter jejuni is a Gram-negative microaerophilic bacterium, which is a major cause of human enterocolitis word-wide (Ketley, 1997). Campylobacter enteritis is characterized by acute abdominal pain and inflammatory diarrhoea. The unpleasant nature of the disease and its increased frequency of reported incidence have resulted in C. jejuni being a major health problem which represents a considerable economic burden in industrialized countries. At present, the development of disease prevention and infection control strategies is hindered by a poor understanding of the pathophysiology and genetics of the organism. Methods of genetic analysis that have been used to characterize other enteric pathogens (e.g. transposon mutagenesis and phage transduction) have not been applied successfully to C. jejuni. Additionally, little is known about the organization of genes on the chromosome. Physical and genetic maps of bacterial genomes are a useful resource for the genetic characterization of an organism and are of particular interest when the sequence of the entire genome is unavailable. Such maps are also helpful in determining genome plasticity and for the construction of ordered vector libraries.

Abbreviation: DIG, digoxigenin.
Variation in genomic maps for different Campylobacter species (C. jejuni and C. coli) as well as for different C. jejuni strains have been reported (Taylor et al., 1992). In the related species Helicobacter pylori, variability in gene order in different strains is well documented and an important factor in genome diversity (Jiang et al., 1996). Physical and genetic mapping studies of several C. jejuni strains, such as UA501 and NCTC 11168 (UA580) (Taylor et al., 1992) and TGH9011 (Kim et al., 1993), have been initiated. However, two different PFGE maps for C. jejuni NCTC 11168 have been reported (Taylor $e t$ al., 1992; Newnham et al., 1996). This could reflect instability of the genome, or merely an improvement in the interpretation of data. In an attempt to unify genetic and biological research on C. jejuni, we have constructed an approximately 18 -fold redundant cosmid library which allowed further revision of the published C. jejuni NCTC 11168 genome map. The newly constructed map, together with further ordering of the cosmid library, will be a useful resource to aid in sequencing the entire genome and to study the pathophysiology of this important pathogen.

\section{METHODS}

Bacterial strains, plasmids and growth. C. jejuni NCTC 11168 was grown on blood-free Campylobacter selective solid media (Oxoid) in $10 \% \quad \mathrm{CO}_{2}, 5 \% \mathrm{O}_{2}$ at $37^{\circ} \mathrm{C}$ for $3 \mathrm{~d}$. 
Escherichia coli DH5 $\alpha$ MCR used for the library construction was grown at $37^{\circ} \mathrm{C}$ in Luria-Bertani broth (LB) or on $1.5 \%$ $(\mathrm{w} / \mathrm{v})$ LB agar (LA) plates supplemented with $25 \mu \mathrm{g}$ kanamycin $\mathrm{ml}^{-1}$. The library was stored at $-80^{\circ} \mathrm{C}$ in 96 -well microtitre plates in LB supplemented with glycerol at $25 \%(\mathrm{v} / \mathrm{v})$. Colonies for hybridization were transferred from the library onto Hybond- $\mathrm{N}$ membranes at a density of 384 per membrane using the Nunc Replication System followed by incubation at $37^{\circ} \mathrm{C}$ on top of LA plates with $25 \mu \mathrm{g}$ kanamycin $\mathrm{ml}^{-1}$ for $24-48$ h.

Construction of cosmid library and DNA manipulation. Tropist 3 cosmid was used for the construction of a genomic library as described previously (De Smet et al., 1993; Henderson et al., 1997). Genomic DNA was partially digested with Sau3A, size-fractionated using a $10-40 \%$ sucrose gradient, and the $25-50 \mathrm{~kb}$ fraction was ligated with $\mathrm{BamHI}$-treated Tropist3. The vector was digested previously with $S c a \mathrm{I}$ and dephosphorylated. Following ligation the library was packaged into phage lambda particles (Stratagene). After transduction into $E$. coli $\mathrm{DH} 5 \alpha$, the cells were plated onto LA plates supplemented with kanamycin. Cosmids were grown in LB containing $50 \mu \mathrm{g}$ kanamycin $\mathrm{ml}^{-1}$ in 96-well microtitre plates and cosmid DNA was isolated either from bacteria grown on LA plates (for restriction enzyme fingerprinting) or from $10 \mathrm{ml}$ of overnight liquid cultures (for sequencing) using the QIAprep Spin Miniprep Kit (QIAGEN). Sequencing was performed on an ABI 373 automatic sequencer using the ABI PRISM Dye Terminator Cycle Sequencing Kit (Perkin Elmer). The vector-derived primers for cosmid sequencing were: TAATACGACTCACTATAGGG (T7) and GATTTAGGTGACACTATAG (SP6).

PFGE. DNA-agarose blocks ( $1 \%$ InCert agarose, FMS) were prepared essentially as described by Taylor et al. (1992). Bacterial DNA in blocks was digested overnight at $37^{\circ} \mathrm{C}$ and $30{ }^{\circ} \mathrm{C}$ with Sall or SmaI, respectively, using 100 units of enzyme per block in $1 \mathrm{ml}$ enzyme buffer. PFGE in $1 \%$ agarose (SeaKem Gold, FMS) was performed using the CHEF DRII system (Bio-Rad) in $0.5 \times$ TBE buffer, using a switch time of $10-35 \mathrm{~s}$, a voltage of $6 \mathrm{~V} \mathrm{~cm}^{-1}$ and a run time of $21 \mathrm{~h}$. DNA bands were visualized by ethidium bromide staining, cut and stored at $4{ }^{\circ} \mathrm{C}$.

Hybridization. DNA in blocks after PFGE was fragmented by a mixture of Sau3A and RsaI restriction enzymes, extracted using the Prep-A-Gene DNA extraction system (Bio-Rad), and fluorescein-labelled using the Gene Images labelling system (Amersham). This system was also used for labelling of the PCR probes corresponding to 'unique' genes murD (CCTAGTCCAGGTTTTCCACC and GCTTTATGAGTGTAGTGTAGGG primers), ung1 (CATCACTCCAGCAAAAAGCGG and GGGTAATTTCCCCAAAGC primers) and $c d t C$ (GCCTTTGCAACTCCTACTGG and CCAAAAGGAAGTTCATCAGC primers). Labelling efficiency was monitored according to the manufacturer's instructions. PCR probes generated from a $2 \mathrm{~kb}$ library using vector-derived primers AK2 (GAGCGGATAACAATTTCACACAGG) and AK3 (GTAAAACGACGGCCAGTG) were digoxigenin (DIG) labelled according to the procedure described for the DIG High Prime DNA Labelling Kit (Boehringer Mannheim). Cells on the membranes were lysed using alkali and after neutralization the released DNA was immobilized using UVirradiation. Hybridization for the Gene Images system was performed in Rapid-Hyb buffer (Amersham) at $65^{\circ} \mathrm{C}$ overnight, and with DIG-labelled DNA in DIG Easy Hyb buffer at $40^{\circ} \mathrm{C}$ overnight. After stringency washes the appropriate detection system (Gene Images or DIG) was used.
Riboprobing. This was performed as described by Bukanov $\&$ Berg (1994). Probes specific for the ends of cloned inserts within the cosmids were generated by in vitro transcription. Cosmid DNA was digested with either HaeIII or ClaI for riboprobes from the T7 promoter, or with EcoRV from the SP6 promoter. The restriction fragments were purified by phenol/chloroform extraction and ethanol precipitation prior to transcription. The template DNA $(1 \mu \mathrm{g})$ was then used in an in vitro transcription reaction as recommended by the supplier (Amersham). Template DNA was removed from the fluororescein labelled probe which was then used directly in the library hybridizations. Cosmids hybridizing to the labelled probe were identified using the Gene Images detection system.

Fingerprinting. Cosmid DNA for restriction analysis was isolated from bacteria grown on agar plates. The choice of HindIII was based on analysis of limited sequencing information of $C$. jejuni available in EMBL and GenBank. HindIII recognition sites were found at a mean frequency of one per $5 \mathrm{~kb}$, which should generate the optimal number of 5-10 fragments on the recombinant cosmids. Cosmids originated from the same hybridization group and sharing several fragments with a total size of at least $5 \mathrm{~kb}$ were considered to have overlapping inserts. This was further confirmed by riboprobing analysis.

\section{RESULTS AND DISCUSSION}

\section{Cosmid library construction}

Initially 1152 colonies were inoculated in LB in 96-well microtitre plates and regrown on three quadra-density filters for hybridization studies. In subsequent experiments 800 cosmids were found to be sufficiently viable for transfer onto nylon filters, resulting in an approximately 18 -fold redundant library. fur, flaAB and cheY probes used in the initial hybridization experiment produced on average $15-18$ positive colonies, indicating that the library is representative. The insert size was found to be in the range between 5 and $40 \mathrm{~kb}$. The smaller size in some cases was shown to be a result of instability, whereas many cosmids with medium and large inserts appeared to be stable.

\section{Hybridization}

A detailed characterization of the cosmid library was performed using hybridization to isolated PFGE fragments. A total of 15 fragments $(9 \mathrm{SmaI}$ and $6 \mathrm{SalI}$ ) was used. As with other bacterial genomes, the C. jejuni chromosome may contain repeated sequences (for example IS elements and rRNA genes) which may result in some ambiguities in the interpretation of cosmid clone hybridization. In most cases, however, we found this background to be negligible, probably because the sizes of possible repeats are usually too small compared to the size of a PFGE fragment. Moreover, we only considered the cosmids giving a strong hybridization signal. Some biased distribution of the cloned fragments towards certain regions was detected. For example, fragments that originated from the SalI-6 and SmaI-6 fragments (corresponding to the same region on the physical map) were overrepresented. In contrast, no cosmids hybri- 
Table 1. Two sets of cosmids hybridizing to the Smal-9 fragment

\begin{tabular}{|lccccccc|}
\hline \multirow{2}{*}{ Cosmid } & \multicolumn{7}{c|}{ Hybridization to PFGE fragment: } \\
\cline { 2 - 8 } & SalI-2 & SalI-3 & Sall-4 & SmaI-3 & Smal-4 & SmaI-5 & SmaI-9 \\
\hline 7G3 & + & - & - & - & - & - & + \\
10B7 & + & - & - & - & - & - & + \\
5E8 & + & - & - & - & + & - & + \\
12F4 & + & - & - & - & + & - & + \\
5B9 & + & + & - & - & - & - & + \\
6G2 & + & + & - & + & - & - & + \\
5H2 & - & - & + & - & - & + & + \\
2A8 & - & - & + & - & - & + & + \\
\hline
\end{tabular}

dized to a SmaI-8 fragment. Interestingly, the SmaI-1 region linked to $S m a \mathrm{I}-8$ was also underrepresented. This could reflect relative instability of some regions of the chromosome cloned in cosmid vectors that may result in gaps during ordering of the cosmid library.

The hybridization results generally agreed with the latest physical map published (Newnham et al., 1996). For example, the cosmids that hybridized to the SalI-1 fragment also hybridized to the SmaI-1, SmaI-7 and SmaI-2 fragments, those that hybridized to SmaI-4 also hybridized to Sall-2, and almost all the cosmids that hybridized to Sall-3 also hybridized to SmaI-3. Similar overlaps were also found for SalI-1/SmaI-6, SalI6/SmaI-6, SalI-5/SmaI-6, Sall-5/SmaI-3 and Sall4/SmaI-5 fragments. However, results of hybridization with the SmaI-9 fragment contradicted the published map of C. jejuni NCTC 11168 (Newnham et al., 1996). This is likely to be the result of ambiguities during construction of the physical map based on partial digestion data (Taylor et al., 1992; Newnham et al., 1996). As several genetic markers are also associated with this fragment, we decided to verify its location by ordering cosmids in this area using hybridization and restriction fingerprinting analyses.

\section{Characterization of the Smal-9 region of the chromosome}

Two major sets of cosmids hybridizing to the SmaI-9 fragment were found (Table 1). Cosmids from one set hybridized to the Sall-2 fragment, whereas cosmids from the other set hybridized to the Sall-4 fragment. One explanation for this observation could be that two SmaI fragments of a similar size originate from different regions of the genome. However, the intensity of the $39 \mathrm{~kb}$ fragment on the PFGE gel corresponds to just one copy of the fragment. Another explanation for this ambiguity is that the SmaI-9 region contains highly conserved repeated DNA sequences. According to the most recently published map of the C. jejuni genome, the SmaI-9 fragment contains an $r r l$ gene (Newnham et al., 1996). As three copies of the gene have been found in different locations on the genome, this would result in hybridization of SmaI-9 to cosmids from other areas containing rRNA genes. Therefore, the ends of the cosmids that hybridized to SmaI-9 were sequenced. Sequences of three 'unique' genes, murD, ung1 and $c d t C$, identified on these cosmids were used to generate PCR probes. The results showed no cross-hybridization with cosmids originated from other regions of the genome. For example, the murD and $c d t C$ probes gave only one positive cosmid each from the Smal-5/Sall-4 and SmaI-4/Sall-2 regions, respectively, as expected. The ung1 probe gave five positives, all from the SmaI$4 /$ SalI-2 region from where it originated. These results confirm that the repeated sequences, rather than a duplicated fragment, caused the discrepancy. This was further verified by sequencing and restriction analysis (see below).

The overlapping rRNA genes in the two sets of cosmids were used as reference points for ordering. The rRNA genes were identified at the ends of some cosmids ( $r r s$ at the T7 end of 6G2, rrl at the SP6 end of 5B9 and $r r l$ at the $\mathrm{T} 7$ end of 5C5) by direct sequencing. The overlapping cosmids $(2 \mathrm{~A} 8,5 \mathrm{H} 2,6 \mathrm{G} 2$ and 5B9) also contained one or two copies of the identical $1.7 \mathrm{~kb} S m a \mathrm{I}$ fragments. Two copies of $1.7 \mathrm{~kb} \mathrm{SmaI} \mathrm{fragments} \mathrm{are} \mathrm{known} \mathrm{to} \mathrm{be} \mathrm{present}$ in the rRNA gene cluster of C. jejuni (z29326.em_ba). The presence of a SalI site inside the operon also allows determination of the orientation of the rRNA genes, since inserts in all four plasmids contained this site. This analysis, along with HindIII restriction fingerprinting, resulted in the map shown in Fig. 1.

\section{Riboprobing}

The derived map was further confirmed in riboprobing experiments using riboprobes generated from ends of the cosmids $5 \mathrm{H} 2,6 \mathrm{G} 2$ and $2 \mathrm{D} 9$. The $\mathrm{T} 7$ probe generated from 6G2 hybridized to three cosmids from the SalI$3 / S m a \mathrm{I}-3$ area according to the location of this area shown on Fig. 1, and also to $5 \mathrm{H} 2$ and $2 \mathrm{~A} 8$ cosmids from another area due to repeated sequences of the rrs gene. T7 transcripts of 2D9 only gave positive signals with 
(a)

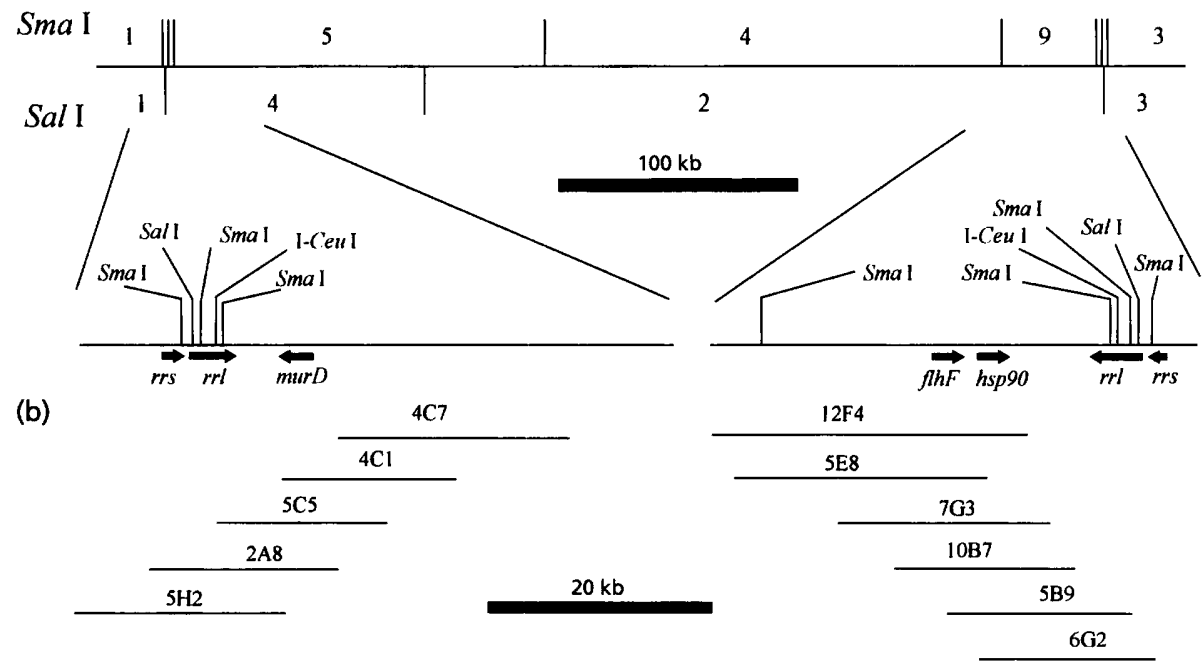

Fig. 1. (a) An approximately $400 \mathrm{~kb}$ fragment of the physical map of the $C$. jejuni NCTC 11168 genome. (b) Fine mapping of the $\sim 60 \mathrm{~kb}$ and $\sim 45 \mathrm{~kb}$ regions using hybridization, fingerprinting analysis and sequencing of selected cosmids. The inserts that hybridized to the Smal-9 fragment are indicated beneath the genetic map.

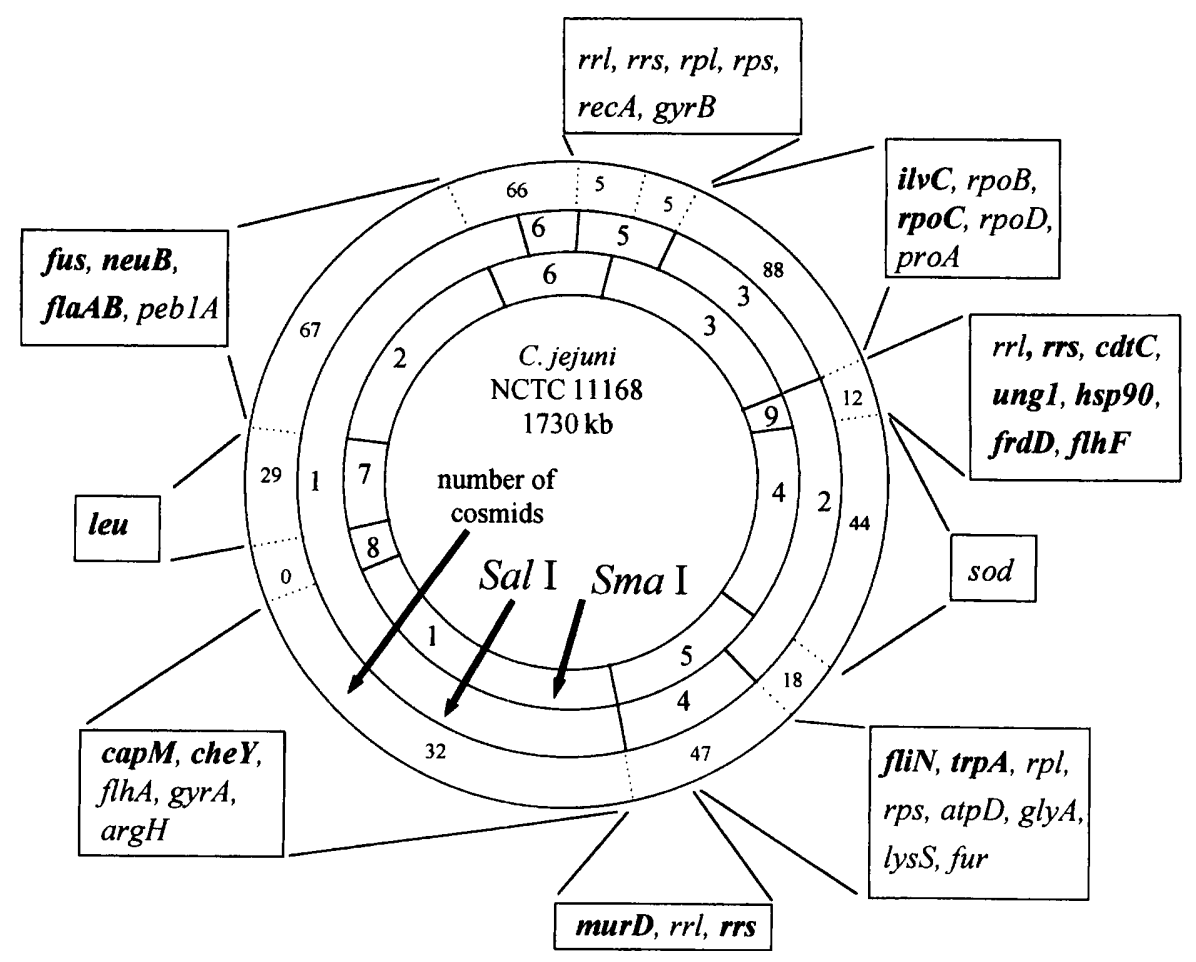

Fig. 2. Physical and genetic map of the $C$. jejuni NCTC 11168 genome. New genes and the genes with modified locations (flaAB and two rrs genes) are indicated in bold and the positions of the other genes corresponding to the previously published map are shown (Taylor et al., 1996). The number of cosmids that hybridized to overlaps of Sall and Smal fragments is shown in the outermost concentric ring. Some of the genes are described in Table 2. The others are: flaAB, which encodes A and B flagellar subunits (Z29327.em_ba); cheY, which encodes a chemotaxis protein (U62036.em-ba); and fur, which is responsible for production of a ferric uptake regulation protein (X78965.em_ba).

cosmids from the SalI-2/SmaI-4 area as expected. The $\mathrm{T} 7$ probe of $5 \mathrm{H} 2$ gave five positive cosmids, all from the SmaI-5/SalI-4 area, also in full agreement with the map shown. On the other hand, the SP6 probe of $5 \mathrm{H} 2$ in addition to SmaI-5/SalI-4 cosmids also hybridized to 5B9 and several cosmids from the SalI-3/SmaI-3 area, 
Table 2. Gene orthologues found after sequencing of selected cosmids from the library

\begin{tabular}{|c|c|c|c|c|c|c|c|c|}
\hline No. & Name & Hybridization group & $\begin{array}{l}\text { Cosmid } \\
\text { size }(\mathbf{k b})\end{array}$ & $\begin{array}{l}\text { Length } \\
\text { (bp) }\end{array}$ & Gene & $\begin{array}{l}\mathrm{EMBL} / \mathrm{SP} \\
\text { Accession } \\
\text { number }\end{array}$ & Gene product & $\begin{array}{c}\text { GC } \\
\text { content } \\
(\mathrm{mol} \%)\end{array}$ \\
\hline 1 & $8 \mathrm{~F} 6-\mathrm{T} 7$ & Sall-3/Smal-3 & $16 \cdot 2$ & 393 & ilvC (Bacillus subtilis) & P37253.sp & $\begin{array}{l}\text { Ketol-acid } \\
\text { reductoisomerase }\end{array}$ & 40 \\
\hline 2 & $1 \mathrm{~F} 3-\mathrm{T} 7$ & SalI-3/SmaI-3 & $13 \cdot 2$ & 381 & $\begin{array}{l}\text { fus (Thermus } \\
\text { thermophilus) }\end{array}$ & P13551.sp & $\begin{array}{l}\text { Elongation factor } G \\
(\text { EF-G) }\end{array}$ & 40 \\
\hline 3 & 1F5-SP6 & Sall-3/SmaI-3 & $30 \cdot 7$ & 327 & $r p o C(E$. coli $)$ & P00579.sp & RNA polymerase & 43 \\
\hline 4 & $6 \mathrm{G} 2-\mathrm{T} 7$ & SmaI-9/SalI-3/SalI-2 & $18 \cdot 8$ & 438 & rrs (C. jejuni) & L14630.em_ba & $16 \mathrm{~S}$ rRNA & 51 \\
\hline 5 & 6G2-SP6 & SmaI-9/Sall-3/Sall-2 & $18 \cdot 8$ & 363 & $\begin{array}{l}\text { hsp90 (Borrelia } \\
\text { burgdorferi) }\end{array}$ & P42555.sp & Heat-shock protein & 33 \\
\hline 6 & $5 \mathrm{H} 2-\mathrm{SP} 6$ & SmaI-9/SmaI-5/SalI-4 & $22 \cdot 9$ & 372 & murD (Bacillus subtilis) & Q03522.sp & $\begin{array}{l}\text { UDP-NAc-Mur-Ala- Glu } \\
\text { synthetase }\end{array}$ & 44 \\
\hline \multirow[t]{2}{*}{7} & 2D9-T7 & SmaI-9/SalI-2/SmaI-4 & $14 \cdot 7$ & 412 & $\begin{array}{l}\text { frdD (Methanococcus } \\
\text { jannaschii) }\end{array}$ & U67466.em_ba & Fumarate reductase & 30 \\
\hline & & & & & $\operatorname{lldP}($ E. coli $)$ & P33231.sp & L-Lactate permease & 37 \\
\hline 8 & 2D9-SP6 & SmaI-9/SalI-2/SmaI-4 & $14 \cdot 7$ & 472 & $\begin{array}{l}\text { Hypothetical } \\
\text { (Methanococcus } \\
\text { jannaschii) }\end{array}$ & $\begin{array}{l}\text { Q57557.sp } \\
\text { Q60301.sptrem } \\
\text { bl }\end{array}$ & Unknown & \\
\hline 9 & $5 \mathrm{E} 8-\mathrm{T} 7$ & SmaI-9/SalI-2/SmaI-4 & $25 \cdot 7$ & 379 & $c d t C(C$. jejuni $)$ & U51121.em_ba & $\begin{array}{l}\text { Cytolethal distending } \\
\text { toxin }\end{array}$ & 31 \\
\hline 10 & $12 \mathrm{~F} 4-\mathrm{T} 7$ & Smal-9/SmaI-4 & $32 \cdot 3$ & 389 & $\begin{array}{l}\text { ung1 (Pseudomonas } \\
\text { aeruginosa) }\end{array}$ & P29950.sp & Uracil-DNA glycosylase & 38 \\
\hline 11 & $5 \mathrm{~B} 9-\mathrm{T} 7$ & SmaI-9/Sall-3/Sall-2 & $16 \cdot 2$ & 457 & flbF (Borrelia burgdorferi) & L75945.em_ba & $\begin{array}{l}\text { Inner membrane } \\
\text { protein }\end{array}$ & 30 \\
\hline 12 & 5B9-SP6 & SmaI-9/SalI-3/SalI-2 & $16 \cdot 2$ & 400 & $r r l(C$. jejuni $)$ & Z29326.em_ba & $23 S$ rRNA & 45 \\
\hline 13 & $5 \mathrm{C} 5-\mathrm{T} 7$ & SalI-4/SmaI-5 & $14 \cdot 5$ & 324 & $r r l$ (C. jejuni) & U09611.em_ba & $23 S$ rRNA & 46 \\
\hline 14 & $11 \mathrm{E} 10$ & Sall-4/SmaI-5 & $19 \cdot 0$ & 375 & $\operatorname{trp} A$ & P50908.sp & $\begin{array}{l}\text { Alpha chain of } \\
\text { tryptophan synthase }\end{array}$ & 35 \\
\hline
\end{tabular}

presumably due to the overlap between the two $\mathrm{rrl}$ genes (Fig. 1).

\section{Use of the library for genetic mapping}

To demonstrate applicability of the library for rapid genetic mapping we chose three recently discovered genes possibly related to virulence, сapM, neuB and fliN, which were identified during sample sequencing of a random $2 \mathrm{~kb}$ pUC18 library (Karlyshev et al., 1997). The capM gene orthologue of Staphylococcus aureus was shown to be involved in the biosynthesis of capsule polysaccharide (Lin $e t$ al., 1994). Although no capsule has been reported for C. jejuni in vitro, it may be expressed in vivo. Alternatively, the capM orthologue may be involved in the biosynthesis of other polysaccharide complexes such as LPS. A putative neuB gene product is involved in sialic acid synthesis in $E$. coli (Annunziato et al., 1995) and may be important in LPS and flagella biosynthesis in C. jejuni, as both of these determinants are sialylated (Guerry et al., 1996; Moran et al., 1996). FliN is a component of the flagellar motor switch of Salmonella typhimurium and plays an important role in bacterial chemotaxis (Kihara et al., 1989).

The PCR products were DIG labelled and hybridized to the library as described in Methods. Seven cosmids that hybridized to the capM probe were found to belong to the SalI-1/SmaI-1 hybridization group, eight cosmids from the SalI-1/SmaI-2 region hybridized to the neuB probe, whereas six positive colonies from the SalI$4 / S m a I-5$ overlap hybridized to the $f l i N$ probe. The results (Fig. 2) were verified by PCR on the extracted cosmid DNAs using gene-specific primers.

Other genetic markers were localized by shotgun sequencing of cosmid DNAs using vector-derived primers T7 and SP6. Some of the genes found are presented in Table 2. As shown in Fig. 2, both $r r s$ and $r r l$ genes were found in the same $S m a \mathrm{I}-9 / S m a \mathrm{I}-3$ area, whereas only $r r l$ was shown previously in this region (Newnham et al., 1996). A locus involved in peptidoglycan biosynthesis (murD) and some potential virulence genes ( $f h F$, $c d t$ Cand $h s p 90)$ were also identified.

The difference between the previously derived physical map of C. jejuni (Newnham et al., 1996) and the one reported here is a clockwise movement of fragments SalI-2 and Sall-4 by $\sim 60 \mathrm{~kb}$. This results in clustering of some SmaI, Sall and I-CeuI sites (which specifically cuts $r r l$ genes) in the regions containing rRNA genes. As a result, the $60 \mathrm{~kb}$ gap between $r r s$ and $r r l$ in the SmaI$5 /$ Sall-4 region has been eliminated. It remains to be determined if the $r r l$ and $r r s$ rRNA genes in the SmaI6/SalI-6/SmaI-5 area are interrupted by $g y r B$, as was reported previously. The revised map also shows that since there is no $60 \mathrm{~kb}$ gap between the SmaI-9/Smal-3 and SalI-2/SalI-3 junctions, the $r p o B$ and $r p o D$ genes 
should be placed in the SmaI-3/SalI-3 overlap. Interestingly, we found another rpo gene $(r p o C)$ in the same area.

\section{Concluding remarks}

An approximately 18-fold redundant cosmid library of C. jejuni NCTC 11168 which covered $98 \%$ of the genome was constructed and partially ordered. Fine physical mapping and ordering of the cosmids along with sequence analysis allowed correction of the published physical map. The library was shown to be useful for rapid mapping of the genes with known sequences. Some known and previously unknown genetic markers, including those encoding potential virulence factors, were mapped. The data should facilitate analysis of the diversity of C. jejuni genome organization and of genes that contribute to disease.

\section{ACKNOWLEDGEMENTS}

We thank Victoria Wilson for excellent technical assistance in the cosmid library construction. The work was supported by the BBSRC UK.

\section{REFERENCES}

Annunziato, P. W., Wright, L. F., Vann, W. F. \& Silver, R. P. (1995). Nucleotide sequence and genetic analysis of the $n e u B$ genes in region 2 of the polysialic acid gene cluster of Escherichia coli K1. J Bacteriol 177, 312-319.

Bukanov, N. O. \& Berg, D. E. (1994). Ordered cosmid library and high-resolution physical-genetic map of Helicobacter pylori strain NCTC 11638. Mol Microbiol 11, 509-523.

De Smet, K. A. L., Jamil, S. \& Stoker, N. G. (1993). Tropist3: a cosmid vector for simplified mapping of both $\mathrm{G}+\mathrm{C}$-rich and $\mathrm{A}+\mathrm{T}$-rich genomic DNA. Gene 136, 215-219.

Guerry, P., Doig, P., Alm, R. A., Burr, D. H., Kinsella, N. \& Trust, T. J. (1996). Identification and characterisation of genes required for post-translational modification of Campylobacter coli VC167 flagellin. Mol Microbiol 19, 369-378.
Henderson, J., Karlyshev, A. V., Wren, B. W. \& Ketley, J. M. (1997). Construction of an ordered cosmid library and genetic map of Campylobacter jejuni NCTC 11168. Society for General Microbiology, 136th Ordinary Meeting, University of Reading, January 1997, abstract M18.

Jiang, Q., Hiratsuka, K. \& Taylor, D. E. (1996). Variability of gene order in different Helicobacter pylori strains contributes to genome diversity. Mol Microbiol 20, 833-842.

Karlyshev, A. V., Ketley, J. M. \& Wren, B. W. (1997). Random shot-gun cloning and sample sequencing of C. jejuni NCTC 11168 genome. Society for General Microbiology, 136th Ordinary Meeting, University of Reading, Janaury 1997, abstract 44.

Ketley, J. M. (1997). Pathogenesis of enteric infection by Campylobacter. Microbiology 143, 5-21.

Kihara, M., Homma, M., Kutsukake, K. \& Macnab, R. M. (1989). Flagella switch of Salmonella typhimurium: gene sequences and deduced protein sequences. J Bacteriol 171, 3247-3257.

Kim, N. W., Lombardi, R., Bingham, H., Hani, E., Loule, H., Ng, D. $\&$ Chan, V. L. (1993). Fine mapping of the three rRNA operons on the updated genomic map of Campylobacter jejuni TGH9011 (ATCC 43431). J Bacteriol 175, 7468-7470.

Lin, W. S., Cunneen, T. \& Lee, C. Y. (1994). Sequence analysis and molecular characterisation of genes required for the biosynthesis of type 1 capsular polysaccharide in Staphylococcus aureus. J Bacteriol 176, 7005-7016.

Moran, A. P., Prendergast, M. M. \& Appelmelk, B. J. (1996). Molecular mimicry of host structures by bacterial lipopolysaccharides and its contribution to disease. FEMS Immunol Med Microbiol 16, 105-115.

Newnham, E., Chang, N. \& Taylor, D. E. (1996). Expanded genomic map of Campylobacter jejuni UA580 and localisation of $23 \mathrm{~S}$ ribosomal rRNA genes by I-CeuI restriction endonuclease digestion. FEMS Microbiol Lett 142, 223-229.

Taylor, D. E., Eaton, M., Yan, W. \& Chang, N. (1992). Genome maps of Campylobacter jejuni and Campylobacter coli. J Bacteriol 174, 2332-2337.

Received 16 July 1997; revised 29 September 1997; accepted 2 October 1997. 